\title{
Food Processing: Another Case Study in Biologically Related Product and Multi-scale Design
}

\author{
Joseph A. Shaeiwitz, Richard Turton \\ West Virginia University
}

Introduction

The profession of chemical engineering is in the midst of a change. Biology is joining math, chemistry, and physics as an "enabling science." Chemical engineers are more often required to design new products rather than new chemical processes. The past generation has seen enormous research advances in the enabling sciences in colloid-scale, nano-scale, molecularscale, and atomic-scale technology.

In response to this expansion of the skills and knowledge required of the $21^{\text {st }}$ century chemical engineer, it is necessary to adopt a new paradigm for chemical engineering education. For example, many programs are now requiring biology classes in addition to the traditional chemistry and physics classes. An increasing number of departments are changing their names to include some reference to biology (e.g., chemical and biochemical engineering, chemical and biomolecular engineering). Product design is either replacing part of or complementing process design in the capstone experience. There is a strong movement to alter the fundamental chemical engineering curriculum common to virtually every program to include the colloid-scale, nanoscale, molecular-scale, and atomic-scale technologies that are at the forefront of chemical engineering research. ${ }^{1}$ This curriculum would replace a significant portion of the macro-scale technology that has been taught in chemical engineering for most of its history as a profession with multi-scale technology, while retaining a sufficient amount of the traditional technology to permit teaching and learning of manufacturing. Traditional course titles may change, reflecting a rearrangement of topics based on length scales. ${ }^{1}$

In any new curriculum paradigm, there will still be a need for a capstone experience. In the new curriculum paradigm, the capstone experience may include design of a product at multiple scales, from the product at the atomic through the colloid scales, as appropriate, and the manufacture of the product at the macro scale. Therefore, a new class of design projects will be needed to replace the traditional continuous chemical manufacturing process that is most often the subject of the capstone design class. This paper describes one such design project assigned to the West Virginia University class of 2005. A different multi-scale, biologically related, product design was completed by the class of $2004 .^{2}$

The Problem

This class was assigned the task of investigating food products. Specifically, they were to identify promising markets for low-carbohydrate and/or low-fat foods and suggest opportunities for a profitable venture to manufacture such products. They were to learn the ingredients in and the methods of manufacture of these food products, particularly the differences in ingredients

Proceedings of the 2005 American Society for Engineering Education Annual Conference \& Exposition Copyright (C) 2005, American Society for Engineering Education 
and in processing required to make low-carbohydrate or low-fat alternatives. The final deliverable was a detailed analysis and design of a process to manufacture a broad spectrum of ice cream products. This included manufacture of ice cream for half-gallon containers containing flavoring, nuts, chocolate chips, etc. Also included was the manufacture of low-fat, fat-free, low-carbohydrate, and lactose-free alternatives. In addition, manufacture of novelties such as ice cream pops and sandwiches was required.

From the perspective of the instructors, three overarching themes exist within this assignment. One is the notion of product design in contrast and in addition to more traditional process design. A product must be designed, but a manufacturing process that differs from a traditional chemical process must also be designed. Another is solving the assigned problem by explicitly addressing phenomena at different length scales. The final theme is the ability of students to teach themselves new material, not normally taught in class, to demonstrate the ability for lifelong learning.

\section{Product Design}

It has been suggested that a general framework for chemical product design includes four steps: (1) need, (2) ideas, (3) screening, and (4) manufacture. ${ }^{3}$ Students identified the need for lowcarbohydrate and low-fat alternative foods. To this end, they learned about the various diets and medical conditions that require individuals to choose these types of foods. The markets for these diet foods were also investigated. Ideas were developed for low-carbohydrate and low-fat food products. A screening method was used that permits the weighting of several criteria in selecting the best alternative. ${ }^{4}$ These criteria included the market for the product in general (total sales of all cookies, for example, not just low-carbohydrate cookies), the market trends of the low-carbohydrate and low-fat alternatives, and the cost of manufacturing the product. These three steps were completed in the fall semester. The "client," a role played by one of the instructors (JAS), chose to manufacture ice cream. Then, the spring semester assignment was to design a process to manufacture ice cream. In order to complete this design, the differences between low-carbohydrate and low-fat ingredients were to be identified along with the differences in processing conditions and procedures required.

\section{Multi-scale Design}

In terms of multi-scale analysis, design of a food product requires design from the molecular scale through the macroscopic scale. Exactly which scales are required depends on the particular product. Table 1 summarizes some examples of the multi-scale processing challenges in food manufacture, all of which were identified by the students.

Although the authors have limited experience with these product design case studies, it is apparent that sometimes information needed at the smaller scales may not be readily available from the usual sources. For example, it is often difficult to extract useful scientific/engineering data from the patent literature, while books and journal articles may not be specific enough for a given product. Solutions to these types of problems include: going into the laboratory and making measurements, teaming-up with a researcher in the area who is willing to lend expertise to the problem, and creative extrapolation of existing data. 
Table 1: Examples of Multi-scale Processing Challenges in Food Manufacturing

\begin{tabular}{|c|c|}
\hline Product & Processing Challenge \\
\hline Ice Cream & $\begin{array}{l}\text { Ice crystal formation must be kept to a minimum. Otherwise, the ice cream } \\
\text { has a grainy texture. }\end{array}$ \\
\hline Ice Cream & $\begin{array}{l}\text { Nut and fruit size must be controlled to control the rheology. Processing } \\
\text { conditions must be controlled to prevent nuts and fruit additives from } \\
\text { becoming soggy. }\end{array}$ \\
\hline Ice Cream & $\begin{array}{l}\text { One method for making low-fat ice cream have the same mouth feel as } \\
\text { regular ice cream is slow churning, a proprietary process of Edy/Dreyers. }{ }^{5} \text { By } \\
\text { churning the ice cream at higher pressures and lower temperatures, smaller, } \\
\text { more dispersed fat globules are formed that have similar mouth feel to regular } \\
\text { ice cream. }\end{array}$ \\
\hline Cookies & $\begin{array}{l}\text { Almond flour is often substituted for wheat flour in low-carbohydrate } \\
\text { cookies. Since almond flour contains more fat, the result is a chewier cookie. }\end{array}$ \\
\hline Cookies & $\begin{array}{l}\text { Granulated sugar is required in cookie manufacture so that the sugar will } \\
\text { spread throughout the cookie during baking. Coarse sugar results in cracking. } \\
\text { This has implications as to which sugar substitute can be used in low- } \\
\text { carbohydrate cookies. }\end{array}$ \\
\hline Cookies & $\begin{array}{l}\text { Reduced-fat cookies require longer baking times to allow the existing fat to } \\
\text { coat the flour and sugar particles. }\end{array}$ \\
\hline Cookies & $\begin{array}{l}\text { For sandwich cookies to stick together, the surface energy of the solid must } \\
\text { be higher than that of the filling. One way to accomplish this is to raise the } \\
\text { temperature of the filling and add more fat to the filling, both of which reduce } \\
\text { its surface energy. (This is also true for ice cream sandwiches.) }\end{array}$ \\
\hline Bread & $\begin{array}{l}\text { Protein and fiber are often substituted for wheat flour in low-carbohydrate } \\
\text { bread. Binding agents are required to hold these ingredients together. Dough } \\
\text { conditioners are added for strength. }\end{array}$ \\
\hline Cereal Bars & $\begin{array}{l}\text { Binders are added to hold the cereal pieces together. They crosslink to form a } \\
\text { flow-resistant structure. There are two common binders. One involves } \\
\text { dipolar interactions between } \mathrm{OH} \text { groups on glucose molecules in the binder } \\
\text { and the cereal pieces. The other involves } \mathrm{COO}^{-} \text {groups bonding covalently } \\
\text { with the cereal pieces. }\end{array}$ \\
\hline
\end{tabular}

Student Results

The method for manufacturing ice cream is very standard. Students had the opportunity to tour a local dairy that manufactures ice cream, so they were able to see the actual equipment used. They did a cost analysis for construction of a plant to manufacture approximately 52 million, 1.75-quart containers of ice cream plus novelties like bars and pops. The manufacturing process has both batch and continuous characteristics. Dissolving of ingredients, pasteurization and homogenization, and ageing are done in a series of tanks. This produces an ice cream base. Then, flavors, pieces (chips, fruits, nuts) are added. Swirling of flavors occurs in the packaging step. When changing between flavors, there is not necessarily a shut down; several packages of ice cream are discarded in what might be called a transition period. However, after a batch of ice 
cream containing allergens (nuts, for example) is made, the equipment must be shut down and cleaned thoroughly. Therefore, batch scheduling becomes important, and a suggested batch schedule for the production facility was developed. For ice cream novelties, the vanilla ice cream is sent to a tunnel extruder where it is enrobed with chocolate (coated), cut, wrapped, and packaged.

An analysis of the economics suggests that the cost to produce a $1.75 \mathrm{qt}$. container of ice cream is on the order of $\$ 1.00$. Typical retail prices range from $\$ 4.50-\$ 6.00$, which include the markup for transportation and profit for the distributor and the retail store.

Students also addressed several of the multi-scale issues specific to ice cream manufacture:

- For example, the contents of low-carbohydrate ice cream increase the viscosity of the ice cream. This causes a back pressure in existing equipment not originally designed for low-carbohydrate ingredients.

- Low-carbohydrate vanilla ice cream looks off white due to the ingredients used; therefore, $\mathrm{TiO}_{2}$ is added as a pigment to make the ice cream look whiter. This colloidal additive can cause equipment and material erosion.

- When a swirled flavor is added, there must be some level of mixing, but not complete mixing.

- Homogenization reduces the size of the fat globules to increase the "creaminess."

Since ice cream is a consumer product, students chose to perform a taste test. Underclassmen not involved in this project were the main participants. Each participant tasted three unidentified samples of ice cream and was asked to rate its taste, texture, and mouth feel. The three samples were the same type of ice cream (flavor, fruit, nut, pieces) with three different types chosen from standard, premium, low-carbohydrate, reduced fat, $98 \%$ fat free, and lactose free.

Finally, students were asked to suggest a new flavor and to suggest the method for manufacture of this flavor. As of the writing of this paper, the flavors under consideration included root beer float (vanilla and root beer flavors), fuzzy navel (peach and orange flavors), and rum and coke (rum, vanilla, cola flavors).

\section{Lifelong Learning}

This project and similar vaguely posed, initially open-ended projects require students to demonstrate the ability for lifelong learning. Students must demonstrate this ability and the instructors have the opportunity to assess this ability. This subject is discussed in more detail elsewhere. ${ }^{6,7}$ A brief synopsis follows.

In the senior year in chemical engineering at West Virginia University, the entire class works on a large project for two semesters under the direction of a student chief engineer. Faculty members play roles in this exercise. One is the client, for whom the students are "hired" to complete a design project (JAS for this project). Another is the "vice-president" of the students" company, who helps the students with technical matters (RT for this project). The chief engineer divides the class into groups, each headed by a group leader. The role of the chief engineer is to 
represent the entire team to the client and to provide leadership from the "big picture" perspective. The group leaders receive assignments from the chief engineer and are responsible for completing the work within their groups. The initial assignment to the class is deliberately vague and open ended. The goal is to force students to define their own work statement, with input from faculty members, and to learn material not normally taught in class. The exact topics students must learn are a function of the project. It is less important what they learn year to year. The goal is to make students realize that they will have to continue learning new material throughout their careers and that they have the ability to do so.

\section{Assessment}

Two assessment measures were used. In one, the two instructors use a rubric to evaluate, separately, all aspects of the final design report and oral presentation submitted by the students each semester. This rubric was developed in the context of more traditional chemical engineering design problems. For example, since biology is not required in our curriculum, it is not listed as a science which students are expected to demonstrate an ability to apply. The ability to learn and to apply biological concepts as needed is evaluated under the ability to learn new material not taught in class. The complete rubric is available on the Web. ${ }^{8}$ Table 2 shows the results, averaged for the two instructors, for the fall semester. The score of 3 indicates meets expectations, and the score of 4 indicates exceeds expectations. Clearly, our assessment of the students suggests that they exhibited superior performance in the ability to teach themselves new material.

Table 2: Assessment Results for Fall Semester Design (Assessment by Faculty)

\begin{tabular}{|l|l|}
\hline Design of equipment, understand interrelationship between equipment in process & 3.0 \\
\hline Apply chemistry, math, physics, engineering science & 3.0 \\
\hline Resolve complex problem into components & 3.0 \\
\hline Apply economic, physical constraints and optimization methods to obtain solution & 3.0 \\
\hline Use of computer-based and other information systems & 3.0 \\
\hline Demonstrate ability to learn new material not taught in class & 4.0 \\
\hline Demonstrate ability to function in assigned role & 3.0 \\
\hline Demonstration of ethical behavior & 3.0 \\
\hline Demonstrate understanding of societal impact and need for assigned design & 3.0 \\
\hline
\end{tabular}

In our student evaluation of instruction, it is possible for the instructor to add an individually defined question, usually specific to a class. One question asked of the class was: In my career I will be required to solve problems appearing to be outside the mainstream of chemical engineering such as food processing. The results were a 4.17 on a 5-point scale, which demonstrates that students appreciate the diversity of industries in which chemical engineers work and the changing paradigm for the profession.

A synopsis of the final student report is posted on our design project Web site. ${ }^{9}$ 


\section{Discussion}

This is one example of a multi-scale, product design project. In this case, students were required to identify new food products, learn about food processing, and learn the effects of the different ingredients on processing steps and processing conditions. The different ingredients, such as sugar substitutes and wheat flour substitutes, are changes on the molecular scale that affect the macroscopic processing steps and conditions. None of these issues are currently part of our curriculum. Therefore, this is also an example of how to incorporate lifelong learning into a capstone experience both to provide students with the opportunity to teach themselves new material and to provide the faculty with the opportunity to assess that skill in students. ${ }^{6}$ However, in a new curriculum, this type of project might be a capstone experience of topics contained in the curriculum.

One can envision similar projects based on the direction of chemical engineering research over the last few decades. One example might be design of a microprocessor and a process for its manufacture. Another might be design of a material, polymer, polymer composite, nanomaterial, etc., with specific properties, and a process for its manufacture. A good source of these design projects might be the research being performed in one's department.

It may seem that design projects of this type are too different from typical capstone design projects for traditionally trained instructors to use in their classes. One method that we have found useful is to invite an expert in the topic of the project to meet with the students to act as a one-time consultant. We usually try to incorporate this visit as part of the graduate seminar series. As early in the project as is possible is best; however, it should be after students have begun research on their own. The consultant meets with the instructors and fills in their knowledge gaps. The consultant also meets with the students to help "jump-start" their research, to suggest sources of information, and to be a general resource for student questions based on their initial research. For this project, the consultant was an alumnus who works in the food processing industry.

\section{Conclusion}

Design of a process to manufacture ice cream was used as a project in a traditional capstone design class. Students were required to teach themselves the necessary information to complete the design. Production of ice cream involves product design, design aspects at the molecular scale, plus it is a biologically related topic. Therefore, it is a useful prototypical design of the future. As the chemical engineering curriculum changes in response to the changes being seen in our profession, similar design projects will find their way into capstone experiences.

\footnotetext{
Bibliography

1. "Frontiers in Chemical Engineering Education," CCR/NSF Workshops, see information at http://web.mit.edu/che-curriculum.

2. Shaeiwitz, J. A. and Turton, R., "Design of a Transdermal Delivery System: A Case Study in Product Design and Multi-scale Design," Proceedings of 2004 ASEE Annual Conference, Session 3413.

3. Cussler, E. L. and Moggridge, G. D., Chemical Product Design, Cambridge University Press, New York, 2001, Chapter 1.

Proceedings of the 2005 American Society for Engineering Education Annual Conference \& Exposition Copyright (C) 2005, American Society for Engineering Education
} 
4. Turton, R., Bailie, R. C., Whiting, W. B. and Shaeiwitz, J. A., Analysis, Synthesis, and Design of Chemical Processes ( $2^{\text {nd }}$ ed.), Prentice Hall PTR, Upper Saddle River, NJ, 2003, Chapter 24.

5. Horovitz, B., "Makers Put Fattening Ice Cream on a Diet," USA Today, June 20, 2004. Article available at http:www.usatoday.com/money/industries/food/2004-06-20-2004-06-21-icecream_x.htm.

6. Shaeiwitz, J. A., Whiting, W. B., and Velegol, D., "A Large-Group Senior Design Experience: Teaching Responsibility and Life-Long Learning," Chemical Engineering Education, vol. 30, no. 1, 1996, pp. 70-75.

7. Shaeiwitz, J. A. and Turton, R., "Life-long Learning Experiences and Simulating Multi-disciplinary Teamwork Experiences through Unusual Capstone Design Projects," Proceedings of 2003 ASEE Annual Conference, Session 1413.

8. http://www.che.cemr.wvu.edu/ugrad/outcomes

9. http://www.che.cemr.wvu.edu/publications/projects/index.php

JOSEPH A. SHAEIWITZ

Joseph A. Shaeiwitz received his B.S. degree from the University of Delaware and his M.S. and Ph.D. degrees from Carnegie Mellon University. His professional interests are in design, design education, and outcomes assessment.

Joe is a co-author of the text Analysis, Synthesis, and Design of Chemical Processes ( $2^{\text {nd }}$ ed.), published by Prentice Hall in 2003.

\section{RICHARD TURTON}

Richard Turton received his B.S. degree from the University of Nottingham and his M.S. and Ph.D. degrees from Oregon State University. His research interests are in fluidization and particle technology and their application to particle coating for pharmaceutical applications. Dick is a co-author of the text Analysis, Synthesis, and Design of Chemical Processes ( $2^{\text {nd }}$ ed.), published by Prentice Hall in 2003.

Proceedings of the 2005 American Society for Engineering Education Annual Conference \& Exposition Copyright (c) 2005, American Society for Engineering Education 